\title{
"Distant.tsul.uz" - online teaching tool during the pandemic at TSUL
}

Farkhod Fazilov, PhD, Senior lecturer of Criminal law, criminology and fight against corruption Department of the Tashkent State University of Law, Uzbekistan, Tashkent, fazilov.farhod@gmail.com ORCID: https://orcid.org/0000-0001-8603-1948

\begin{abstract}
Background: The lockdown across the country due to the coronavirus pandemic forced all educational institutions, including the Tashkent State University of Law (TSUL) conduct online classes to compensate for the loss of the academic period. Among all the available applications, the dedicated platform "Distant.tsul.uz" turned out to be a more convenient application with many built-in functions. After a few months of use platforms for classes in the criminal law department, a feedback survey was conducted to find out the effectiveness of online classes and the advantages and disadvantages of the platform.
\end{abstract}

Material and Methods: The questionnaire, which contained both objective and open questions, was for more than a hundred 2nd year students who took online classes conducted by the department of Criminal law, criminology and fight against corruption.

Results: According to students, taking online classes was the best way to use isolation time (51\%). The students found the platform very user-friendly and easy to use. They felt that using anytime, anywhere and constant access to materials (91\%) were advantages of the platform. Lack of free internet, network problems are the main problems in using this tool.

Conclusion: A dedicated university platform is the best way to leverage the time of the pandemic to offset the loss of academic performance. The website "distant.tsul.uz" (1) is an effective teaching tool.

Keywords: platform; pandemic; lockdown; criminal law; online.

Received: 05.12.2020 Accepted: 10.01.2021 $\quad$ Published: 06.02.2021

\section{Introduction}

Every person is entitled to education, and the State must guarantee free general education. The official literacy rate in Uzbekistan is 99 percent.

Until mid-March, residents of Uzbekistan - a doubly landlocked state - experienced the coronavirus epidemic with some degree of surprise: the epidemic, which originally found in China, circled the center of Asia and began to spread in Europe. On March 15, Uzbekistan officially announced the detection of the first case of coronavirus infection in a citizen who arrived from France (2).

On March 15, 2020, Uzbekistan announced nationwide isolation due to the coronavirus pandemic. By the decision of the Special Commission, the educational process at all universities was continued online, including at the Tashkent State University of Law.

The project "Innovative form of expansion the availability of legal education through the "Electronic University" platform is aimed at:

- optimization of educational and administrative procedures in the Tashkent State University of Law;

- digitalization of education, the implementation of modern information technologies; the improvement of students' skills of self-education and self-development;

- development of a distance learning system;

- the creation of special targeted programs to enhance the involvement of women in the legal profession;

- improving the quality of educational services;

- improving the quality of education;

- simplification of the university management process through the automation of workflow (3).

A platform is a site that allows for teachers to post lectures, video lessons, cases, tests, conduct online lectures, show presentations or videos, and for students to receive the necessary information.

University distance learning platform:

1. works with absolutely any information data formats.

2. video content, training materials and manuals. No need to go to the library, to the methodologist.

3. uses video content, infographics, introduces clarity.

4. allows to use game elements, reward system.

5. available on smartphones. 
6. allows to monitor the progress of both an individual student and a group, and adjust the educational process for each student.

7. has a wide functionality for communication with teachers, classmates, the administration of the university.

Research indicates that individuals prefer educational programs, "that are flexible with time and location (4). An app in mobile can improve the online learning experience by improving communication (5).

Today in Uzbekistan there are many applications for online education and training, for example, Zoom, Telegram, etc. But they all require a lot of Internet traffic, ask for the connection of platform functions for additional services, and have problems with confidentiality. The university platform is devoid of all this.

Criminal law, criminal procedure, criminology and forensic science are considered the main disciplines for our faculty. A topic like criminology needs clear concepts. We used the platform as online educational platform for teaching 2nd year students. After using this app for 4 months, we have collected student feedback on online lessons.

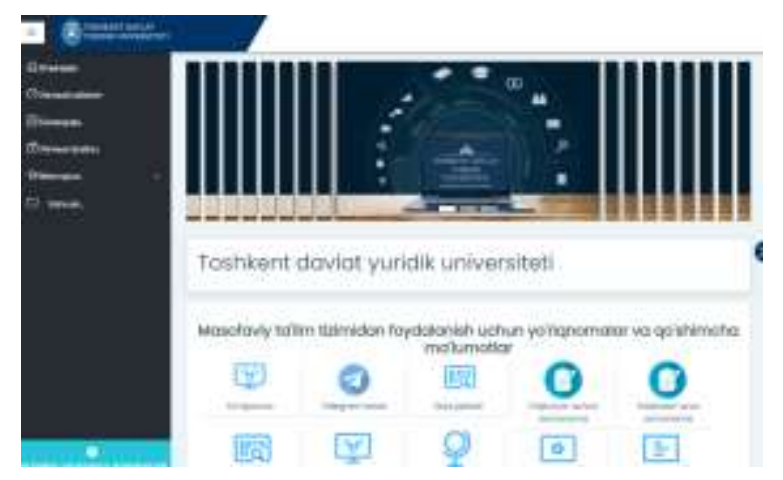

\section{Goals and objectives}

1. Examine the effectiveness of online learning.

2. Get student feedback on the platform.

3. Get an opinion on online education at the University

4. Understand how to improve the learning process

\section{Materials and methods}

Second year students of the Faculty of Criminal Justice $(n=105$, boys $=70$, girls $=35)$

\section{Methodology}

The platform served as the main venue for the seminars. We posted legal cases on criminal law, and students answered them online. Lectures were held in video mode.

\section{Statistical analysis}

the collected data was analyzed using Telegram.

\section{Results}

According to students, taking online classes was the best way to use isolation time (51\%). The students found the platform very user-friendly and easy to use. They felt that using anytime, anywhere and constant access to materials (91\%) were advantages of the platform. Lack of free internet, network problems are the main problems in using this tool. 


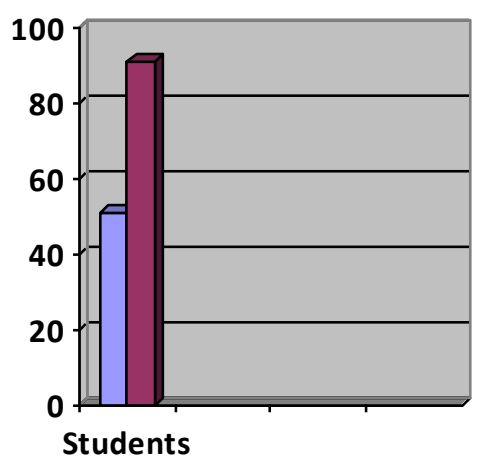

(\%)
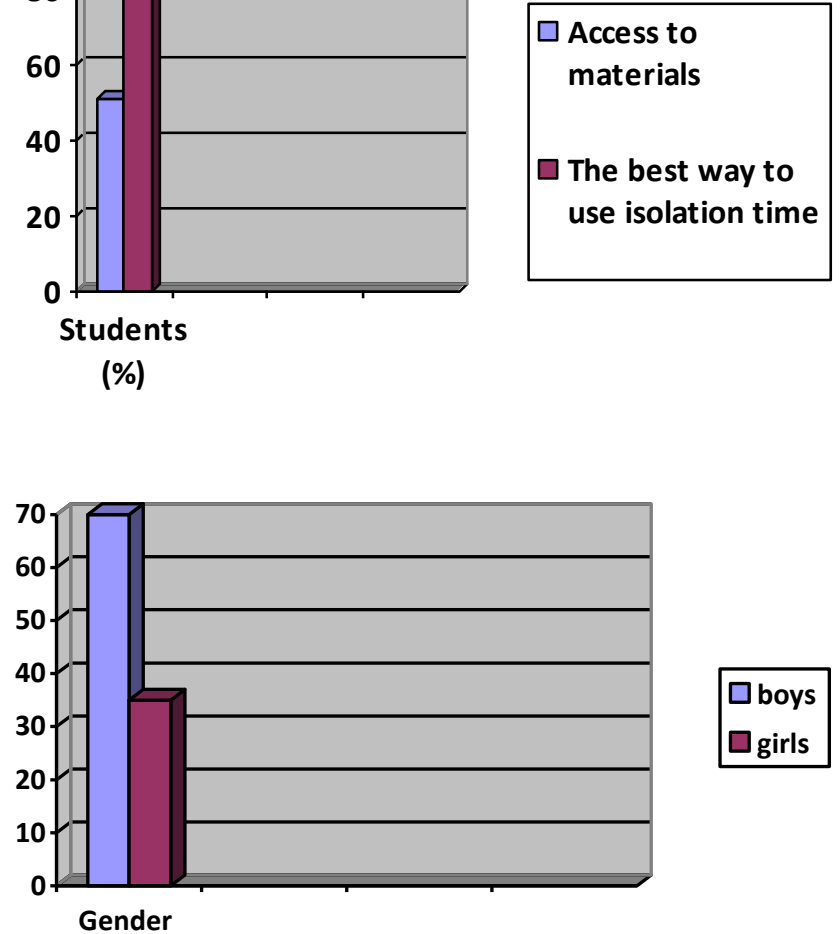

\section{Discussion}

Advantages of distance learning on the platform

1. Availability

Studying remotely, you can gain knowledge from anywhere in the country or even the world.

2. Saving money and time

Studying remotely, the student does not depend on transport. In addition to saving money, this allows you to save a lot of free time.

3. The platform, unlike other social networks and tools, works faster. Internet traffic is saved. The protection of personal data is maintained.

4. It is convenient for teachers and university administration to monitor progress and attendance.

E-learning provides a more efficient, cheaper, and potentially better alternative. E-learning needs to be introduced and made readily accessible to everyone (6).

Cons of distance learning on the platform.

1. Lack of personal communication

Full-time education is valuable not only for a set of knowledge. An important element of offline learning is personal communication. Receiving a traditional higher education, the student cooks for several years in the seething cauldron of university life. He interacts with teachers and classmates in an informal setting. Such communication can generate amazing ideas and radically change the fate of people. 2. Lack of control

The lack of constant control from the teacher is a minus, which can be easily confused with a plus. But it's not that simple. At first, the student may feel that the lack of control gives him additional freedom. In fact, distance learning requires strong motivation and rigid self-discipline from the student. This is especially true of the part of the work on the platform, when students have to answer questions within a few days. It is difficult to control who completed the task. Students often have the same answers to case studies. It is difficult to establish who is plagiarized in the answer.

\section{Conclusion}

The COVID-19 pandemic has modified education dramatically, whereby giving rise to E-learning. Students and academics can be confused to handle this situation which they weren't ready for (7).

University platform is a convenient way to use the time of the pandemic to compensate for the loss of the academic period. 


\section{References}

1. http://distant.tsul.uz/

2. https://review.uz/en/post/government-and-business-joint-efforts-to-support-the-vulnerablegroups-of-the-population-during-the-covid-19-pandemic-in-uzbekistan

3. https://tsul.uz/en/informatsiya/events/elektronnii-universitet

4. Ross- Gordon, Jovita M. Research on Adult Learners: Supporting the Needs of a Student Population that Is No Longer Nontraditional. Winter. 2011;13(1):26-29

5. Fuegen S. The Impact of Mobile Technologies on Distance Education. TechTrends. 2012;56:49-53.

6. Suresh M, Vishnu Priya V, Gayathri R. Effect of e-learning on academic performance of undergraduate students. Drug Invention Today [Internet]. 2018; 10(9).

7. Sinclaire JK. Student satisfaction with online learning: Lessons from organizational behavior. Research in Higher Education Journal. 2011 Jun 1; 11:1. 